
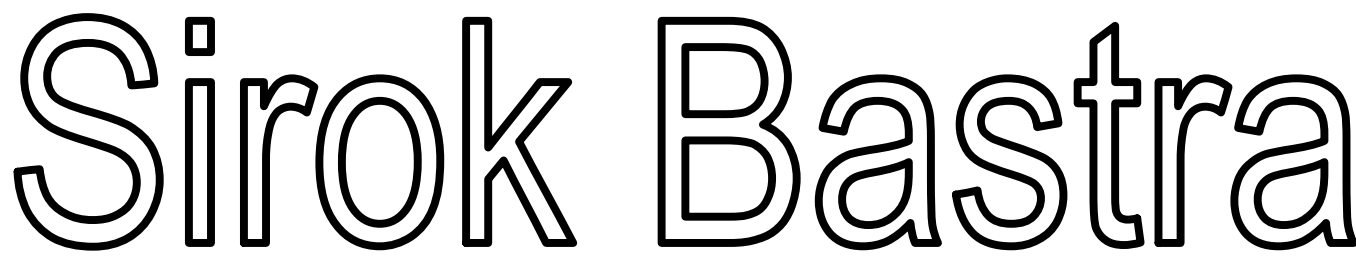

J URNAL ILMIAH KEBAHASAAN DAN KESASTRAAN

\begin{tabular}{|c|c|c|c|c|c|}
\hline $\begin{array}{c}\text { Sirok Bastra } \\
\text { Jurnal Kebahasaan dan } \\
\text { Kesastraan }\end{array}$ & Volume 5 & Nomor 2 & $\begin{array}{c}\text { Hlm. } \\
101-196\end{array}$ & $\begin{array}{c}\text { Pangkalpinang, } \\
\text { Desember } \\
2017\end{array}$ & $\begin{array}{c}\text { ISSN } \\
2354-7200\end{array}$ \\
\hline
\end{tabular}

KANTOR BAHASA KEPULAUAN BANGKA BELITUNG 


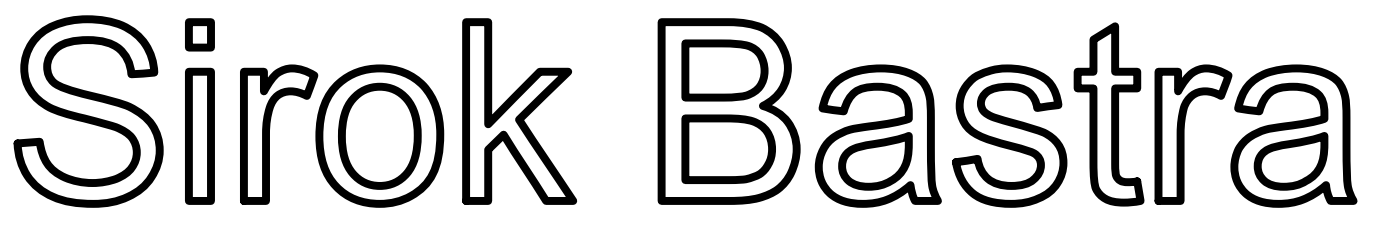

\section{J URNAL ILMIAH KEBAHASAAN DAN KESASTRAAN}

Jurnal ini merupakan wadah informasi kebahasan, kesastraan, dan pengajarannya yang memuat hasil penelitian, studi kepustakaan, dan tulisan ilmiah bidang kebahasan dan kesastraan serta pengajarannya. Sirok Bastra terbit dua kali setahun, yakni Juni dan Desember, serta terbit sejak Juni 2013.

\section{Penanggung Jawab}

Kepala Kantor Bahasa Kepulauan Bangka Belitung

Drs. Hidayatul Astar, M.Hum.

\section{Mitra Bestari}

Prof. Dr. Agus Nuryatin, M.Hum. (Bidang Sastra dan Pengajarannya)

Prof. Amrin Saragih, Ph.D., M.A. (Bidang Bahasa dan Pengajarannya)

Dr. Felicia Nuradi Utorodewo, M.Hum. (Bidang Bahasa dan Pengajarannya)

Dr. Pujiharto, M.Hum. (Bidang Sastra dan Pengajarannya)

\section{Pemimpin Redaksi}

Rahmat Muhidin, S.S.

\section{Penyunting}

Dr. Asyraf Suryadin, M.Pd.

Prima Hariyanto, S.Hum.

Sarman, S.Pd.

\section{Perancang Sampul}

Feri Pristiawan, S.S.

\section{Pengatak}

Dewi Septi Kurniawati, S.Kom.

\section{Kesekretariatan \\ Ria Anggraini, S.E. Juliati, S.E.}

\section{Alamat Redaksi dan Penerbit}

Kantor Bahasa Kepulauan Bangka Belitung

Jalan Letkol Saleh Ode No. 412, Kota Pangkalpinang, Prov. Kepulauan Bangka Belitung Telepon (0717) 438455, Faksimile(0717)9103317, Pos-el: sirokbastra@gmail.com, sirokbastra@kemdikbud.go.id

Pemuatan suatu tulisan dalam jurnal ini tidak berarti redaksi menyetujui isi tulisan tersebut. Isi tulisan menjadi tanggung jawab penulis. Tulisan telah ditinjau dan diulas oleh mitra bestari. Setiap karangan dalam jurnal ini dapat diperbanyak setelah mendapat izin tertulis dari penulis, redaksi, dan penerbit. 


\section{PENGANTAR}

Puji syukur ke hadirat Pemilik dan Pencipta semesta ini yang memiliki kuasa atas diri-Nya sendiri. Dialah Tuhan Yang Maha Esa yang telah memberikan rahmat dan hidayah-Nya sehingga Volume 5 Nomor 2 Jurnal Sirok Bastra Tahun 2017 dapat terbit tepat pada waktunya.

Pada edisi ini dimuat sepuluh tulisan, yakni lima tulisan kebahasaan, empat tulisan kesastraan, dan satu tulisan pengajaran sastra.

Dalam penelitiannya, Hotnida Novita Sary menganalisis iklan komersial Meikarta yang telah membuat perusahaan tersebut berhasil mencatatkan penjualan yang fantastis. Penelitian yang dilakukannya menggunakan pisau bedah analisis wacana kritis Fairclough (1989). Iklan Meikarta membandingkan kesuperioritasan mereka dibandingkan kota metropolitan lain, seperti Jakarta. Meikarta juga menanamkan ideologi bagi masyarakat kota besar bahwa kota metropolitan saat ini sudah tidak aman, kotor, dan macet.

Dalam makalahnya, Hidayatul Astar mengkaji realisasi konsep bahasa Indonesia ke dalam bahasa Rejang. Menurutnya, masyarakat Rejang tidak memiliki konsep (kata atau istilah) yang cukup untuk mewakili pikiran dan perasaan tertentu ketika berkomunikasi, terutama yang terkait dengan konsep kehidupan modern atau yang sesuai dengan perkembangan zaman. Karena itu, bahasa Rejang perlu memungut atau mengambil dari bahasa lain, khususnya dari bahasa Indonesia. Realisasi bentuk konsep yang ditemukan adalah realisasi tanpa perubahan dan realisasi dengan perubahan. Berdasarkan data, realisasi perubahan dalam sebuah konsep dapat satu kali atau lebih. Realisasi perubahan itu berupa penghilangan, penggantian, dan penambahan bunyi vokal atau konsonan tertentu pada posisi tertentu. Terjadinya perubahan realisasi bunyi bahasa Indonsia ke dalam bahasa Rejang disebabkan oleh keinginan penutur bahasa Rejang dan adaptasi terhadap bunyi yang sudah ada.

Dalam kajiannya, Mardi Nugroho membahas pembentukan kata dalam bahasa Talondo di Sulawesi Barat. Hasil analisis data menunjukkan bahwa ada tiga macam cara pembentukan kata dalam bahasa Talondo, yaitu afiksasi, reduplikasi, dan pemajemukan. Pembentukan kata dengan afiksasi terdiri atas pembentukan kata dengan prefiksasi, konfiksasi, infiksasi, dan sufiksasi. Pembentukan kata dengan reduplikasi terdiri atas reduplikasi murni, reduplikasi sebagian, dan reduplikasi yang berkombinasi dengan afiksasi.

Dalam kajiannya, Muhammad Fadely membahas makna dan bentuk pemakaian eufemisme dan disfemisme dalam feature karya Ruslan Ismail Mage yang bermanfaat bagi pengajaran bahasa Indonesia dan pengembangan bahasa di media massa cetak. Hasil analisis menunjukkan bahwa pemakaian eufemisme lebih banyak daripada pemakaian disfemisme. Berdasarkan simpulan tersebut, peneliti menyarankan bahwa dalam menyampaikan suatu informasi kepada khalayak umum hindari tulisan-tulisan yang dapat mengaburkan dan tidak terus terang demi maksud-maksud tertentu.

Dalam kajiannya, Asri Soraya Afsari membahas karakteristik bahasa yang digunakan dalam iklan komersial ponsel yang berada di Kota Bandung. Hasil penelitian menunjukkan bahwa bentuk dan fungsi bahasa yang digunakan dalam iklan ponsel di Kota Bandung berupa penulisan huruf kapital secara keseluruhan dan penulisan huruf kapital pada awal kata. Bahasa iklan ponsel memiliki fungsi informatif dan konatif (persuatif).

Dalam tulisannya, Erwin Wibowo mendeskripsikan makna semiotik budaya Lampung yang ada di dalam antologi Kitab Cerpen Perempuan di Rumah Panggung. Hasil penelitian mengungkapkan ikon, indeks, dan simbol budaya Lampung melalui pendekatan semiotik yang dipakai dalam Kitab Cerpen Perempuan di Rumah Panggung karya Isbedy Stiawan ZS dan memberi deskripsi tentang ikon, indeks, dan simbol tesebut.

Dalam penelitiannya, Prima Hariyanto membahas penokohan dalam Kitab Omong Kosong yang mengambil cerita epos Ramayana. Dalam novel ini, pengarang mengubah pola cerita. Tokoh sentral dalam cerita ini bukan lagi Rama dan Sinta, tetapi Maneka dan Satya. Ceritanya bukan lagi kisah cinta Rama dan Sinta, tetapi kisah perjalanan Maneka dan Satya dalam mencari Kitab Omong Kosong ciptaan Hanoman. Tokoh Rama tidak lagi diceritakan sebagai kesatria yang baik, tetapi sebagai raja yang membawa bencana bagi rakyat di muka bumi.

Dalam kajiannya, Dian Anggraini mengkaji intertekstual lima puisi Indonesia yang berisi tentang sosok wanita yang disebut ibu, yaitu "Ibu Dehulu" (Amir Hamzah), "Ibu” (Chairil Anwar), "Sajak Ibu” (Wiji Thukul), 
"Bunda Air Mata" (Emha Ainun Najib"), dan "Ibu” (K.H. Mustofa Bisri). Hasil telaah itu membuktikan bahwa kelima puisi tersebut merupakan mosaik, kutipan-kutipan, penyerapan, dan perspektif yang beragam terhadap sosok ibu. Setiap penyair mengungkapkan sisi ibu dari pandangan yang berbeda.

Dalam kajiannya, Yuliadi M.R. membahas makna ground dalam cerpen "Uak dan Burung Gagak" dengan pendekatan objektif melalui teori semiotik Pierce. Berdasarkan kajian, terungkap bahwa makna ground dalam cerpen Uak dan Burung Gagak, yaitu ground qualisign berupa warna hitam, sinsign berupa suara koakkoak, dan legisign berupa perilaku mengitari rumah.

Dalam tulisannya, Abdul Azis dan Hajrah membahas dongeng sebagai bahan pembelajaran di sekolah dasar. Data penelitian ini adalah dongeng Cerita Si Jingkiriq, I Kukang, Nenek Pakande, La Dana dan Kerbaunya, dan Puang Tedong. Hasil analisis data dan temuan menunjukkan bahwa rata-rata penilaian responden untuk dongeng sebesar 3,75 (kategori layak dijadikan bahan ajar). Bahan ajar yang dapat digunakan untuk tingkat SD adalah dongeng yang isinya sesuai dengan karakteristik, pengalaman, dan kebutuhan siswa.

Kami mengucapkan terima kasih kepada para penulis yang telah bersedia menerbitkan karya mereka pada edisi ini. Para penulis merupakan peneliti, pakar, dosen, dan mahasiswa dari berbagai perguruan tinggi dan instansi. Terima kasih juga kami sampaikan kepada para mitra bestari kami yang telah memberi ulasan terhadap tulisan-tulisan yang masuk ke redaksi.

Demi memenuhi keberagaman isi dan penulis, Sirok Bastra membuka kesempatan bagi para peneliti dan penulis menyampaikan hasil penelitian dan pemikiran mutakhir dalam bidang kebahasaan, kesastraan, dan pengajarannya. 


\section{UCAPAN TERIMA KASIH UNTUK MITRA BESTARI}

Redaksi Sirok Bastra mengucapkan terima kasih kepada para mitra bestari yang telah meninjau, menimbang, dan mengulas makalah-makalah yang diterbitkan dalam Sirok Bastra Volume 5 Nomor 2, edisi Desember 2017, yakni

Prof. Dr. Agus Nuryatin, M.Hum.

Bidang Sastra dan Pengajarannya

Universitas Negeri Semarang

Semarang, Jawa Tengah

Prof. Amrin Saragih, Ph.D., M.A.

Bidang Bahasa dan Pengajarannya

Universitas Negeri Medan

Medan, Sumatra Utara

Dr. Felicia Nuradi Utorodewo, M.Hum.

Bidang Bahasa dan Pengajarannya

Universitas Indonesia

Depok, Jawa Barat

\section{Dr. Pujiharto, M.Hum.}

Bidang Sastra dan Pengajarannya

Universitas Gadjah Mada

Yogyakarta, Daerah Istimewa Yogyakarta 


\section{DAFTAR ISI}

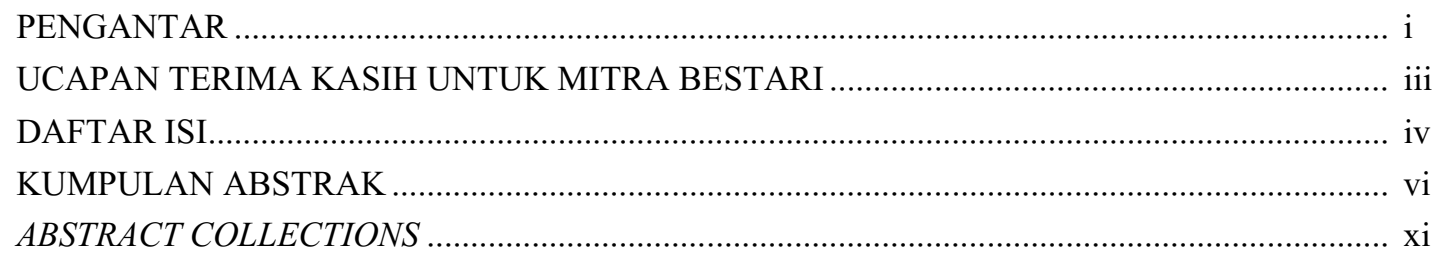

ANALISIS WACANA KRITIS IKLAN KOMERSIAL MEIKARTA

(Critical Discourse Analysis of Meikarta Commercial Advertising)

Hotnida Novita Sary $101-111$

REALISASI KONSEP BAHASA INDONESIA DALAM BAHASA REJANG

(Realization of Indonesian Concept Into Rejang Language)

Hidayatul Astar. $113-121$

PEMBENTUKAN KATA DALAM BAHASA TALONDO

(The Word Formation in Talondo Language)

Mardi Nugroho $123-129$

EUFEMISME DAN DISFEMISME PADA FEATURE-FEATURE KARYA RUSLAN ISMAIL MAGE

(Euphemism and Disphemism in The Features by Ruslan Ismail Mage)

Muhammad Fadely $131-139$

KARAKTERISTIK PENGGUNAAN BAHASA DALAM IKLAN PONSEL DI KOTA BANDUNG

(The Characteristic of Language Usage on Mobile Phone Advertisement in Bandung) Asri Soraya Afsari $141-151$

SIMBOL BUDAYA LAMPUNG DALAM KITAB CERPEN PEREMPUAN DI RUMAH PANGGUNG KARYA ISBEDY STIAWAN Z.S.: KAJIAN SEMIOTIKA

(Lampung Cultural Symbols in Kitab Cerpen Perempuan di Rumah Panggung by Isbedy Stiawan Z.S.: a Semiotic Analysis)

Erwin Wibowo $153-161$

PENOKOHAN DALAM KITAB OMONG KOSONG KARYA SENO GUMIRA AJIDARMA (Characterization in Kitab Omong Kosong by Seno Gumira Ajidarma)

Prima Hariyanto $163-169$

WANITA ISTIMEWA: KAJIAN INTERTEKSTUAL TERHADAP PUISI-PUISI TENTANG IBU

(Special Woman: Intertextual Study of Poems About Mother) 
BURUNG GAGAK SEBUAH TANDA: MAKNA GROUND DALAM CERPEN UAK DAN BURUNG GAGAK

(Brids Crow A Sign: Ground Meaning in Uak and Burung Gagak Short Story)

Yuliadi M.R.

DONGENG SEBAGAI BAHAN PEMBELAJARAN BAHASA INDONESIA DI SEKOLAH

DASAR

(Folktale as Indonesian Language Learning Material in Elementary School)

Abdul Azis dan Hajrah

$191-196$ 
Asri Soraya Afsari: Karakteristik Penggunaan Bahasa dalam Iklan Ponsel di Kota Bandung

\title{
KARAKTERISTIK PENGGUNAAN BAHASA DALAM IKLAN PONSEL DI KOTA BANDUNG
}

\section{The Characteristic of Language Usage on Mobile Phone Advertisement in Bandung}

\author{
Asri Soraya Afsari \\ Fakultas Ilmu Budaya, Universitas Padjadjaran \\ Jalan Raya Bandung Sumedang Km 21, Hegarmanah, Jatinangor, Jawa Barat \\ Pos-el: asri.s.afsari@unpad.ac.id.
}

(diterima 9 Juni 2017, disetujui 17 September 2017, revisi terakhir 29 November 2017)

\begin{abstract}
Abstrak
Penelitian ini bertujuan untuk mengetahui bagaimana karakteristik bahasa yang digunakan dalam iklan komersial ponsel yang berada di Kota Bandung. Karakteristik bahasa yang dimaksud menyangkut bentuk dan fungsi. Teori yang diterapkan dalam analisis bersandar pada Kridalaksana (2001) dan Zaimar \& Harahap (2011). Metode penelitian yang digunakan adalah kualitatif-deskriptif. Adapun teknik yang ditempuh dilakukan melalui langkahlangkah: pengumpulan data iklan menggunakan random sampling, pengklasifikasian data, analisis data berdasarkan teori, serta penyimpulan hasil penelitian sebagai jawaban terhadap masalah yang diteliti. Metode yang digunakan adalah metode distribusional. Hasil penelitian menunjukkan bahwa bentuk dan fungsi bahasa yang digunakan dalam iklan ponsel di Kota Bandung berupa penulisan huruf kapital secara keseluruhan dan penulisan huruf kapital pada awal kata. Bahasa iklan ponsel memiliki fungsi informatif dan konatif (persuatif) .

Kata kunci: karakteristik bahasa, iklan ponsel, bentuk bahasa, fungsi bahasa
\end{abstract}

\begin{abstract}
This research has a purpose to know language characteristic on mobile phone advertisement in Bandung. Language characteristic in this research related to form and function. The analitical applied theory is based on Kridalaksana (2001) and Zaimar \& Harahap (2011). This research use qualitative-descriptive method. The technique is done through these steps: collecting the advertisement data using random sampling, classifying the data, analysing the data based on the theory, and concluding the result as the answer of the problem. This research used distributional study method. The result indicates that the language form and function used on the mobile phone advertisement in Bandung is either entirely capital letters on the writing or only on the initial word. The language function on the text is informative and conative (persuative).
\end{abstract}

Keywords: language characteristic, mobile phone ad, language form, language function

\section{PENDAHULUAN}

\subsection{Latar Belakang}

Sebagai makhluk sosial, manusia senantiasa berinteraksi baik secara individu maupun kelompok. Interaksi yang berlangsung tentu menggunakan alat komunikasi. Bahasa adalah salah satu alat komunikasi manusia dan telepon merupakan alat komunikasi hasil teknologi yang berguna untuk memudahkan berlangsungnya sebuah komunikasi antarindividu tanpa harus bertemu langsung atau

bertatap muka. Kebutuhan akan sarana komunikasi (hasil teknologi) pada masa sekarang begitu penting. Salah satu manfaat yang dirasakan dari semakin pesatnya kemajuan ilmu pengetahuan dan teknologi terutama dalam bidang komunikasi adalah membuat jarak interaksi dan gerak hidup manusia yang begitu jauh, kini terasa begitu dekat.

Kehadiran alat komunikasi berupa telepon seluler (ponsel) mampu membuat jarak yang begitu jauh itu terasa begitu dekat. Jarak pemisah berupa lautan, pegunungan, pulau, negara, bahkan benua, bukan lagi penghalang untuk menjalin komunikasi dengan siapa saja dan kapan saja. Bertalian dengan ini, para produsen ponsel berlomba-lomba menciptakan ponsel canggih dengan berbagai 
model. Salah satu media yang dimanfaatkan oleh produsen ponsel guna mendorong produk yang mereka buat agar laku di pasaran adalah melalui media iklan.

Martadi (1999) dalam Widyatama (2011) menyebutkan bahwa iklan merupakan bagian dari pemasaran produk karena mendorong penjualan. Selanjutnya, Williams (1993) dan Mary Cross (1996) dalam Widyatama (2011) menjelaskan bahwa iklan merupakan merupakan komponen vital dalam organisasi dan reproduksi kapital. Iklan sebagai bagian dari kapitalisme karena menciptakan need, want, dan buy melalui materi iklan yang impacfull maupun reach, frecuency, serta continuity di media yang efektif dan efisien (Martadi, 2001).

Penelitian ini memfokuskan pada pengkajian wacana iklan komersial ponsel yang berlokasi di Kota Bandung. Iklan ponsel yang dianalisis adalah produk telepon seluler yang berasal dari dalam dan luar negeri. Dengan demikian, penelitian ini berpusat pada bagaimana penggunaan bahasa yang digunakan dalam iklan ponsel.

\subsection{Rumusan Masalah}

Penelitian ini akan menjangkau hal-hal sebagai berikut.

1. Bentuk bahasa apa saja yang terdapat dalam iklan ponsel di Kota Bandung?

2. Fungsi bahasa apa saja yang terdapat dalam iklan ponsel di KotaBandung?

\subsection{Tujuan}

Berdasarkan rumusan masalah yang telah dikemukakan, penelitian ini bertujuan untuk mendeskripsikan bentuk dan fungsi bahasa yang terdapat dalam iklan ponsel di Kota Bandung.

\subsection{Manfaat}

Penelitian ini dapat berguna bagi para produsen iklan terutama iklan komersial. Para produsen iklan diharapkan dapat mengetahui bagaimana penggunaan bahasa Indonesia standar dalam pembuatan iklan. Dengan demikian, pembuatan sebuah iklan tidak hanya bertujuan untuk promosi semata tanpa memperhatikan aspek bahasa.

1.5 Metode
Metode yang digunakan adalah pendekatan kualitatif deskriptif. Penggunaan metode deskriptif dipertimbangkan atas pemusatan perhatian pada ciri-ciri, dan sifat-sifat data bahasa secara alami sehingga dihasilkan pemerian data bahasa yang aktual untuk dapat dianalisis (Djajasudarma, 2010:14). Dalam penelitian ini dilakukan pendeskripsian karakteristik bahasa yang terdapat dalam iklan komersial ponsel yang berada di Kota Bandung. Perspektif waktu yang diterapkan di dalam penelitian ini bersifat sinkronis (pada kurun waktu tertentu). Teknik yang ditempuh dilakukan melalui langkah-langkah: pengumpulan data iklan menggunakan random sampling, pengklasifikasian data, analisis data berdasarkan teori yang menyangkut bentuk dan fungsi, serta penyimpulan hasil penelitian sebagai jawaban terhadap masalah yang diteliti. Metode kajian yang digunakan adalah distribusional.

\section{KERANGKA TEORI}

\subsection{Pengertian Iklan}

Pengertian iklan begitu beragam, hal ini disebabkan adanya perbedaan sudut pandang, misalnya masyarakat Amerika dan Inggris menyebut iklan sebagai advertising. Istilah ini berasal dari bahasa Latin, yaitu ad-vere yang berarti mengoperkan pikiran dan gagasan kepada pihak lain. Di Perancis, iklan disebut dengan reclamare yang berarti meneriakkan sesuatu secara berulang-ulang. Di Belanda, iklan disebut sebagai adverrentie, sedangkan bangsa Latin menyebutnya dengan istilah advertere yang berarti menuju ke depan. Bangsa Arab dan Timur Tangah menyebut iklan dengan istilah i'lan. Istilah inilah yang kemudian diadopsi dan dipakai di Indonesia untuk menyebut nama iklan, tetapi dengan pelafalan khas Indonesia. Suara sengau diganti dengan pelafalan huruf $/ \mathrm{k} /$ yang lebih jelas sehingga kata i'lan diucapkan menjadi iklan.

Di Indonesia, Masyarakat Periklanan Indonesia (MPI) mengartikan iklan sebagai segala bentuk pesan tentang suatu produk atau jasa yang disampaikan lewat suatu media dan ditujukan kepada sebagian atau seluruh masyarakat. 
Sementara istilah periklanan diartikan sebagai keseluruhan proses yang meliputi persiapan, perencanaan, pelaksanaan, dan pengawasan penyampaian iklan (Bedjo Riyanto, 2001 dalam Widyatama, 2006: 26-28).

\subsection{Media Iklan}

Tinarbuko (2008); Suryadi (2011); dan Widyatama (2011) menjelaskan bahwa dalam iklan, ranah kreatif desain atau advertising meliputi kampanye iklan komersial dan perancangan iklan layanan masyarakat. Aplikasi perancangan dan perencanaan desain baik iklan komersial maupun iklan layanan masyarakat (nonkomersial) senantiasa melibatkan seluruh media periklanan yang meliputi tiga bagian. Pertama, media iklan lini atas (above the lineadvertising), yakni jenis-jenis iklan yang diasosiasikan menggunakan sarana media massa komunikasi audio visual, misalnya surat kabar, majalah, tabloid, iklan radio, televisi, bioskop, internet, telepon seluler. Kedua, media iklan lini bawah (below the line advertising), yaitu kegiatan periklanan yang diasosiasikan tidak menggunakan media massa cetak dan elektronik. Media yang digunakan berkisar pada printed ad seperti poster, brosur, leaflet, folder, flyer, catalog, dan merchandising seperti payung, mug, kaos, topi, dompet, pin, tas, kalender, buku agenda, pulpen, dan gantungan kunci. Ketiga, new media seperti ambient media, guerillas edvertising, theatrical advertising, dan adman.

\subsection{Fungsi Iklan}

Widyatama (2011) menjelaskan bahwa iklan menempati posisi yang strategis dan mampu ikut menggerakan dan menggairahkan dunia industri. Oleh karena itu, iklan menjadi sangat penting dalam memasarkan suatu produk. Bahkan ia seolah-olah menjadi minyak pelumas yang menjalankan roda industri agar tetap berputar. Tanpa iklan, roda industri berputar perlahan, macet, bahkan tidak bergerak sama sekali. Dengan kata lain, iklan mampu mengemban sejumlah fungsi yang sangat penting. Fungsi-fungsi yang dimiliki oleh iklan, antara lain sebagai berikut.
1. Sebagai media komunikasi dari pihak produsen atau pembuat pesan kepada konsumen atau khalayak penerima pesan. Fungsi komunikasi tersebut meliputi: fungsi memberi informasi, fungsi persuasi, fungsi pengingat, fungsi pemercepat keputusan, fungsi pembangun citra, dan fungsi pencegah citra.

2. Sebagai media pendidikan yang digunakan oleh produsen atau komunikator terhadap konsumen atau khalayaknya. Fungsi pendidikan ini dapat meliputi pemahaman baru tentang masalah tertentu dari produsen, perubahan sikap, sistem nilai dan perilaku tertentu dari konsumen ke arah perubahan sikap sistem nilai dan perilaku tertentu yang lain sesuai dengan harapan produsen, serta perubahan pola pikir khalayak ke arah kondisi tertentu sebagaimana dikehendaki komunikator.

3. Sebagai media yang berfungsi ekonomi di tengah masyakarat. Dengan iklan, banyak masyarakat yang mengetahui dan mengonsumsi produk sehingga pada gilirannya mendatangkan keuntungan bagi produsen. Karena iklan pula, frekuensi penggunaan produk bisa bertambah, penggunaan dari benda yang sama lebih bervariasi, pembelian jumlah produk bertambah, yang menambah keuntungan dari sisi ekonomi. Banyak keuntungan ekonomi yang bisa diraih oleh konsumen, di antaranya konsumen memperoleh informasi secara instan tentang produk yang baik dan harga yang sesuai dengan kemampuan, konsumen tahu tempat-tempat penjualan produk yang terdekat, konsumen lebih hemat dalam penggunaan waktu dan tenaga, pengetahuan konsumen tentang produk menjadi bertambah;

4. Sebagai media sosial. Iklan berfungsi sebagai penyampai pesan sosial, baik disadari atau tidak. Melalui iklan, masyarakat dapat tergerak memberikan bantuan kemanusiaan.

5. Sebagai media penghibur bagi khalayak.

\subsection{Bahasa Iklan}

Bahasa dan iklan merupakan dua hal yang tidak terpisahkan. Bahasa berperan penting dalam penciptaan sebuah iklan, baik iklan komersial 
maupun iklan nonkomersial. Bahasa yang dipakai dalam iklan mempunyai ciri tertentu. Ciri-ciri tersebut antara lain disunting sesuai dengan tujuannya; kaya dan menawan yang secara spesifik bermaksud menarik dan mendapatkan perhatian kita; menuntut perhatian kita untuk melengkapi iklan tersebut; dan bersifat sederhana (O'Neill, 1986:117 dalam Suwandi, 2008:108).

\subsection{Bentuk Kata}

Bentuk (form) adalah petampakkan atau rupa satuan gramatikal atau leksikal dipandang secara fonis atau grafemis (Kridalaksana, 2001:28). Bagi teks tertulis, tipografi, misalnya tulisan yang besar, cetak miring atau tebal, juga susunan teks (seperti CV) memegang peranan penting dalam komunikasi taklangsung sehingga meskipun tidak dapat dicek karena pengirim tidak dapat mengontrol reaksi si penerima, teknik-teknik tipografi ini dapat mempermudah berlangsungnya komunikasi. Kemampuan teks untuk dapat diterima dengan mudah, menyebabkan kemungkinan pemahaman pesan yang lebih besar dan cepat (Zaimar dan Harahap, 2011:66).

\subsection{Fungsi Bahasa}

Jacobson (1960) menyatakan bahwa bahasa memiliki beberapa fungsi, yaitu fungsi referensial, fungsi emotif, fungsi konatif atau persuatif, fungsi metalinguistik, fungsi fatik, dan fungsi puitik. Zaimar dan Harahap (2011:58) menjelaskan bahwa jenis wacana menurut fungsi bahasanya meliputi (a) referensial, yakni digunakan jika pengirim tidak ingin tampil, tetapi ingin menonjolkan acuan hal yang dibicarakannya; (b) ekspresif, yakni berpusat pada pengirim pesan, ia mengemukakan gagasan atau pendapatnya terhadap isi pesan; (c) konatif, yakni digunakan apabila si pengirim ingin memengaruhi si penerima; (d) fatik, yakni berpusat pada saluran komunikasi. Semua unsur bahasa yang ada dalam teks digunakan untuk menjalin hubungan antara pengirim dan penerima (baik secara fisik maupun psikologis), mempertahankannya ataupun memutuskannya; (e) puitik, yakni menonjolkan unsur pesan dalam komunikasi. Semua unsur bahasa yang ada dalam teks memberikan suatu tambahan nilai keindahan dalam pesan; (f) metalinguistik, yakni berpusat pada kode. Semua unsur bahasa yang terdapat dalam teks digunakan untuk memberi penjelasan atau keterangan tentang kode yang digunakan oleh pengirim, termasuk ke dalam fungsi metalinguistik. Di samping memiliki fungsi informatif, bahasa iklan juga mengandung fungsi persuatif. Hal ini bertujuan untuk memengaruhi masyarakat agar tertarik kepada produk yang diiklankan (Mulyana, 2005:65).

\section{HASIL DAN PEMBAHASAN}

Berdasarkan medianya, iklan komersial ponsel yang dikaji dalam penelitian ini termasuk dalam lini atas (above the lineadvertising). Menurut segi media cetaknya, iklan ponsel tersebut adalah kelompok iklan display karena iklan ponsel yang berada di kota Bandung ini didominasi oleh ilustrasi visual. Suryadi (2011) menjelaskan bahwa bentuk penyajian iklan display sangat beragam tergantung pada nilai kreativitas dan estetika yang diinginkan oleh pengiklan.

Dari segi katakteristik bahasa, keanekaragaman sebuah iklan komersial dapat berkaitan dengan perbedaan bentuk bahasa. Bentuk bahasa dalam iklan ponsel di Kota Bandung, di antaranya berupa penggunaan huruf kapital secara keseluruhan pada setiap kata kalimat dan penggunaan huruf huruf kapital hanya pada setiap awal kata atau kalimat, sedangkan ukuran huruf yang digunakan bervariasi. Berikut disajikan uraian mengenai bentuk dan fungsi bahasa yang terdapat dalam iklan ponsel di Kota Bandung. 


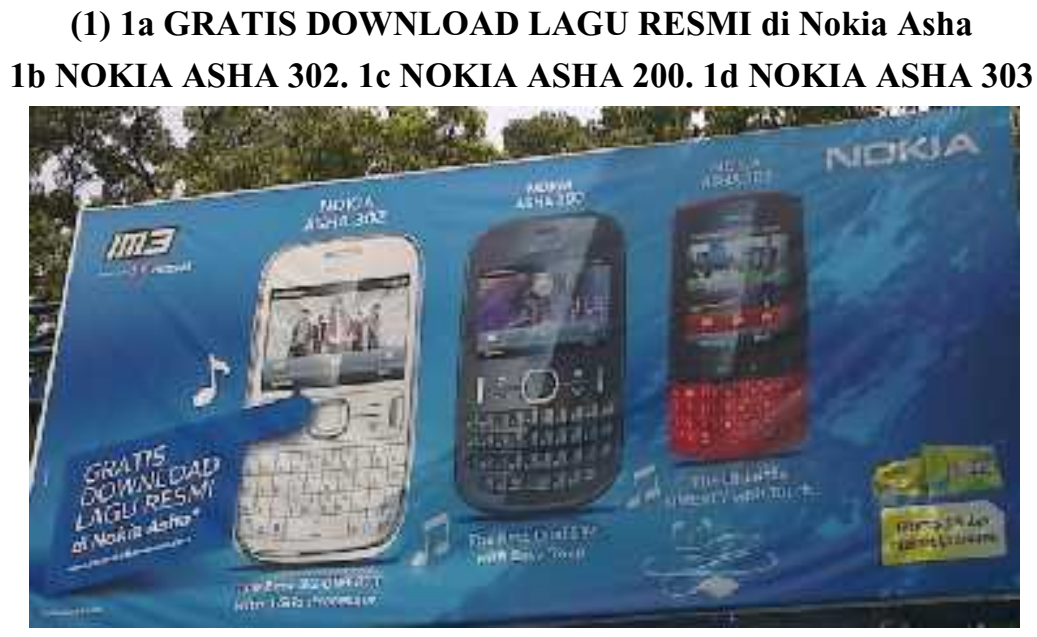

Sumber: Perempatan Jalan Purnawarman

Data (1) 1a GRATIS DOWNLOAD LAGU RESMI di Nokia Asha.1b NOKIA ASHA 302. 1c NOKIA ASHA 200.1d NOKIA ASHA 303 termasuk dalam iklan (above the lineadvertising). Data (1) memiliki struktur GRATIS DOWNLOAD (P) LAGU RESMI (O) di Nokia Asha (K1). Ib NOKIA ASHA 302 (K2) .1c NOKIA ASHA 200 (K3) 1d. NOKIA ASHA 303 (K4). Dengan demikian, data (1) berpola (P-O-K1), (K2), (K3), (K4). Huruf dalam iklan data (1) memakai huruf kapital pada empat kata pertama dan huruf kecil di awal kata, khususnya yang berfungsi sebagai objek. Hal ini bertujuan sebagai penekanan, penegas, dan menarik perhatian pembaca. Kalimat pada data iklan (1) memiliki fungsi informatif yakni dengan membeli produk-produk Nokia Asha pembeli dapat mengunduh lagu resmi secara cumacuma.

\section{(2) ilexus my style mengucapkan Selamat Menunaikan Ibadah Puasa}

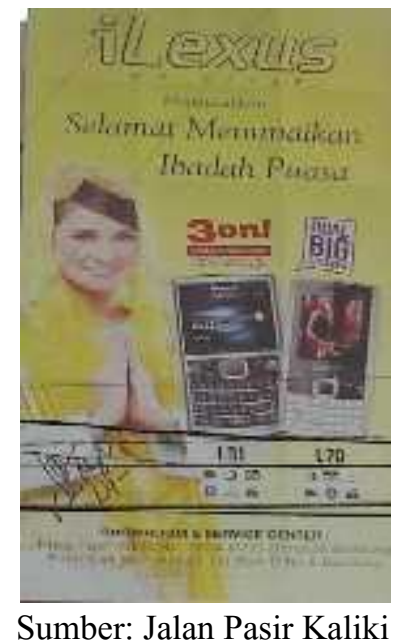

Data (2) ilexus my style mengucapkan Selamat Menunaikan Ibadah Puasa termasuk ke dalam iklan (above the lineadvertising). Data (2) memiliki struktur ilexus my style (S) mengucapkan (P) Selamat Menunaikan Ibadah Puasa (O). Dengan demikian, data (2) berpola (S-P-O). Huruf dalam data iklan (2) ini memakai huruf kecil dan kapital di awal kata, khususnya yang berfungsi sebagai objek dan bertujuan untuk menarik perhatian pembaca.

Bahasa yang dipakai dalam data (2) adalah bahasa baku dan digabung dengan dua kata bahasa asing my style untuk lebih menarik konsumen (fungsi persuatif). Kalimat Selamat Menunaikan Ibadah Puasa digunakan untuk tujuan promosi 
produk ponsel ini. Pembuat iklan memanfaatkan momen bulan Ramadan sebagai salah satu strategi untuk meningkatkan promosi. Dari segi penulisan, $i$ Lexiusd an Selamat Menunaikan Ibadah Puasa ditulis agak miring bertujuan untuk hubungan keakraban. Selain itu, dalam data (2) terdapat campur kode berwujud frasa, yaitu my style, dijual $B I G$, dan 3 On di antara tulisan bahasa Indonesia yang digunakan dalam iklan $i$ Lexius.

\section{(3) Samsung Bikin gaulmu makin Sik Asik}

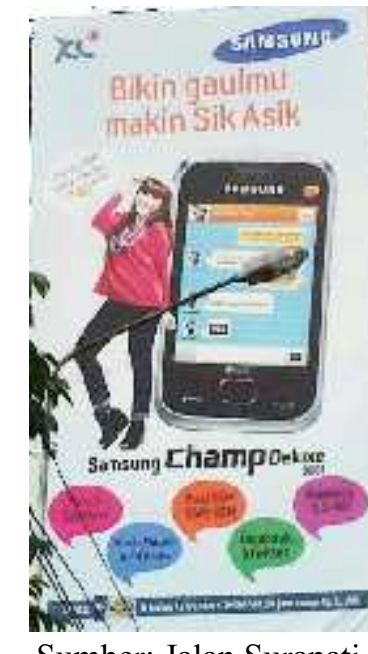

Sumber: Jalan Surapati

Data (3) Samsung Bikin gaulmu makin Sik Asik termasuk dalam iklan (above the line advertising). Data (3) memiliki struktur Samsung (S) bikin (P) gaulmu (O) makin Sik Asik (K). Dengan demikian, struktur data iklan (3) berpola (S-P-O-K). Huruf dalam data (3) memakai huruf kapital di awal kata agar menarik perhatian pembaca. Upaya lain yang dibuat agar dapat menarik minat pembaca adalah dengan menulis kalimat Samsung Bikin gaulmu makin Sik Asik dan kata Champ yang menunjukkan tipe ponsel Samsung dalam ukuran huruf yang lebih besar dari kata-kata lainnya. Dari jenis teks menurut fungsi bahasanya, data (3) memiliki fungsi konatif, yaitu si penerima dilibatkan dalam penyampaian pesan. Dalam data (3) si penerima dilibatkan secara langsung dalam proses komunikasi. Penggunaan kata ganti persona kedua - $m u$ pada data (3) membuat pembaca merasa bahwa iklan itu ditujukan pada dirinya.

\section{(4) Flexi mulai Rp.40rb GRATIS NELPON, SMS, INTERNET SETAHUN}

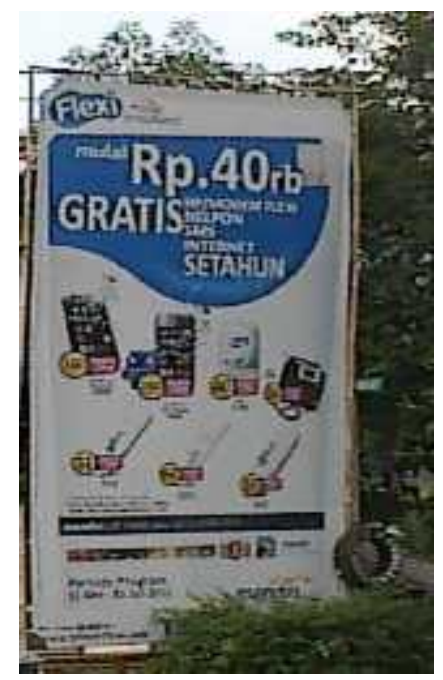

Sumber: Jalan Diponegoro 
Data (4) Flexi mulai Rp.40rb GRATIS NELPON, SMS, INTERNET SETAHUN termasuk dalam iklan (above the lineadvertising). Data (4) memiliki struktur Flexi (S) mulai Rp.40rb (K) GRATIS NELPON, SMS, INTERNET SETAHUN (P). Dengan demikian, pola iklan (4) adalah (S-K-P). Huruf pada data (4) sebagian besar huruf kapital dan sebagian kecil memakai huruf kecil sebagai penekanan dan penegas.

Dalam iklan (4), ukuran huruf kata Flexi, Rp.40rb, GRATIS, dan SETAHUN lebih besar dari kata yang lain. Hal ini bertujuan untuk lebih menarik dan terlihat jelas bagi pembaca atau konsumen. Selain itu, tujuan ditulisnya kata GRATIS dan SETAHUN dalam ukuran yang lebih besar adalah untuk menginformasikan kepada pembaca bahwa produk ponsel dalam iklan (4) menawarkan kelebihan dan keuntungan bagi siapa saja yang berminat untuk membeli ponsel ini. Dengan demikian, kalimat pada data iklan (4) memiliki fungsi informatif.

(5) 5a Jangan ketinggalan. Pakai BlackBerry Curve ${ }^{\mathrm{TM}}$ baru 5c BlackBerry Curve ${ }^{\mathrm{TM}}$. 5d BlackBerry Curve ${ }^{\mathrm{TM}} \mathbf{9 2 2 0}$

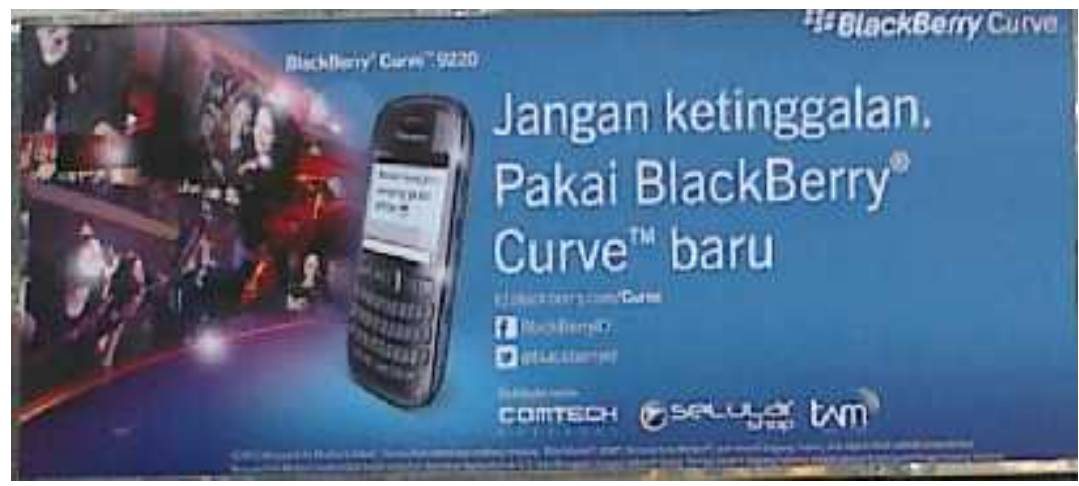

Sumber: Jalan Purnawarman

Data (5) 5a Jangan ketinggalan. 5b Pakai BlackBerry Curve ${ }^{T M}$ baru 5c BlackBerry Curve ${ }^{T M}$ dan 5d BlackBerry Curve ${ }^{T M} 9220$ termasuk iklan (above the line advertising). Data (5) memiliki struktur Jangan ketinggalan (K) 5b Pakai (P) BlackBerry Curve $^{T M}$ baru (O) 5c BlackBerry Curve $^{T M}(\mathrm{~K})$ dan 5d BlackBerry Curve ${ }^{T M} 9220(\mathrm{~K})$. Dengan demikian, pola iklan (5) adalah (K-P-O-K). Huruf pada data (5) memakai huruf kecil. Huruf kapital hanya di awal kata dan awal nama produk.
Hal ini bertujuan untuk menjalin keakraban. Penulisan Jangan ketinggalan 5b Pakai BlackBerry Curve $^{T M}$ baru dibuat dalam ukuran yang besar bertujuan agar terlihat jelas sehingga mudah untuk menarik perhatian pembaca. Kalimat pada data iklan (5) memiliki fungsi informatif dan persuatif yakni menginformasikan sekaligus mengajak pembaca supaya jangan sampai tertinggal menggunakan produk terbaru yang ditawarkan BlackBerry. 
(6) 6a MOTOROLA TAMPIL BEDA. MENYENANGKAN. MELAKUKAN BANYAK HAL. 6b MOTOROLA FIRE. 6c MOTOROLA RAZR. 6d MOTOROLA EX119.

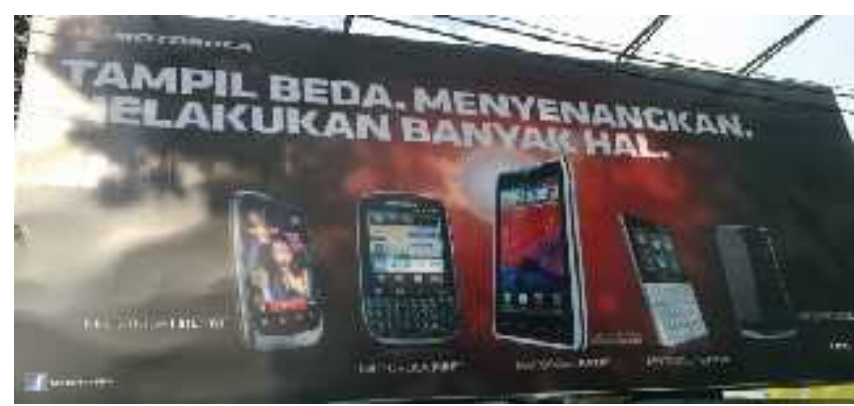

Sumber: Perempatan Jalan Riau

Data (6) 6a MOTOROLA (S) TAMPIL BEDA. MENYENANGKAN. MELAKUKAN BANYAK HAL. 6b MOTOROLA FIRE (S), 6c MOTOROLA RAZR (S), 6d MOTOROLA EX119 (S) termasuk iklan (above the line advertising). Data (6) memiliki struktur MOTOROLA (S), TAMPIL BEDA (P1). MENYENANGKAN (P2). MELAKUKAN BANYAK HAL (P3). 6b MOTOROLA FIRE (K1), 6c MOTOROLA RAZR (K2), 6d MOTOROLA EX119 (K3). Dengan demikian, struktur iklan (6) adalah (SP1-P2-K1-K2-K3). Semua huruf dalam iklan (6) menggunakan huruf kapital yang berfungsi sebagai penekanan dan penegas, sedangkan ukuran huruf nama produk terlihat lebih kecil dari huruf yang lain untuk memberikan kesan penasaran dan menarik bagi pembaca yang melihat iklan tersebut. Kalimat pada iklan (6) memiliki fungsi informatif yakni menginformasikan bahwa produk terbaru ponsel Motorola berbeda dari yang lain dan juga persuatif karena memengaruhi pembaca agar membeli ponsel tersebut melalui pernyataan bahwa menggunakan ponsel Motorola akan menyenangkan dan bisa melakukan banyak hal.

(7) MAXTRON HP TV Cherry Belle hanya Rp.249.000

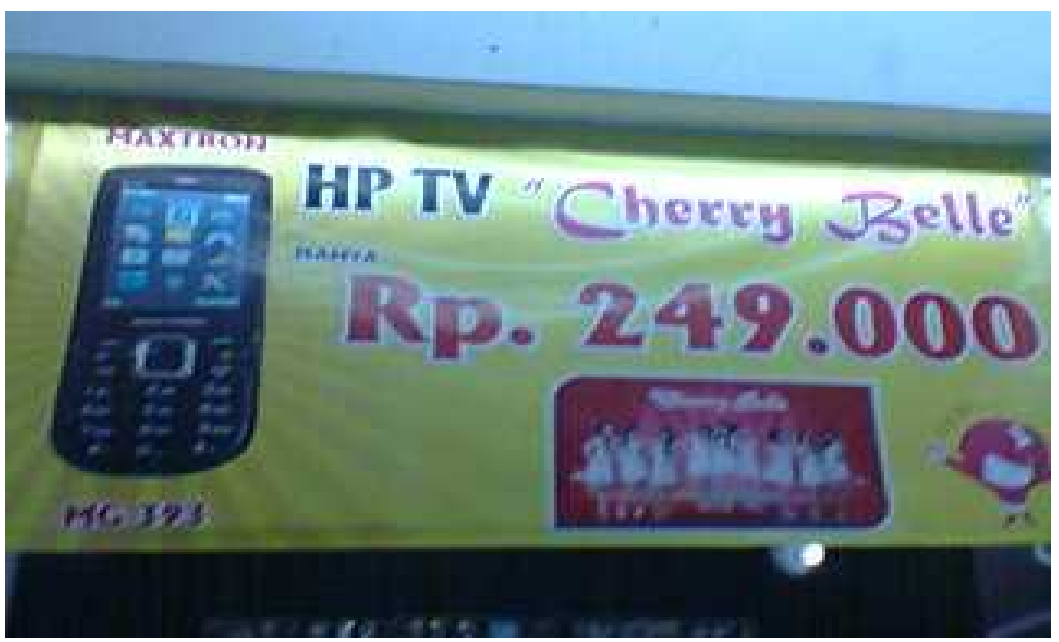

Sumber: Jalan Margacinta

Data (7) MAXTRON HP TV Cherry Belle harga Rp.249.000 termasuk iklan (above the line advertising). Data (7) memiliki struktur MAXTRON HP TV Cherry Belle (S) hanya Rp.249.000 (P). Dengan demikian, struktur iklan (7) adalah (S-P).
Huruf dalam iklan (7) memakai huruf kapital untuk nama produk dan sebagian memakai huruf kecil. Bahasa yang digunakan adalah bahasa baku. Penulisan Rp249.000 dibuat dalam ukuran besar. Hal ini bertujuan untuk menarik perhatian pembaca. 
Selain itu, penulisan $H P T V$ dibuat agak besar untuk menunjukkan bahwa produk ponsel MAXTRON selain sebagai ponsel juga dapat berfungsi sebagai TV dalam ukuran mini. Dari segi kalimat, data iklan (7) berfungsi informatif. Adapun Cherry Belle digunakan sebagai ikon produk MAXTRON bertujuan untuk meningkatkan promosi termasuk ke dalam fungsi persuatif. Cherry Belle merupakan nama sebuah girlsband yang saat itu banyak digandrungi oleh kalangan remaja. Cherry Belle dicetak dengan agak miring untuk menunjukkan bahwa girlsband ini beranggotakan remaja-remaja wanita yang lucu dan manis.

\section{(8) CROSS JUSTIN BIEBER}

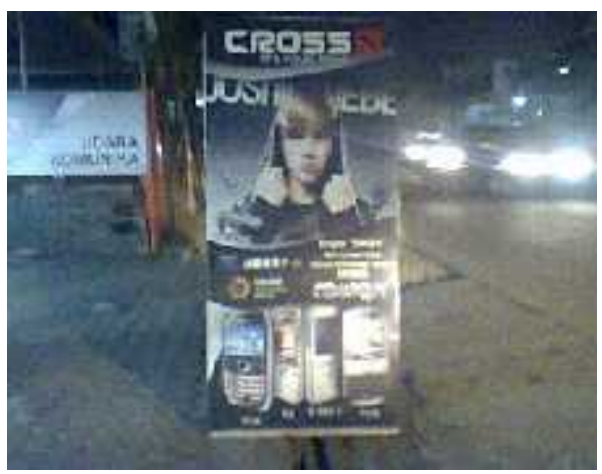

Sumber: Jalan Ciwastra

Data (8) hanya terdapat kata CROSS dan JUSTIN BIEBER. Data (6) memiliki struktur CROSS (N). Dengan demikian struktur iklan (8) hanya berupa kata yang berkelas nomina. JUSTIN BEIBER dimanfaatkan oleh pembuat iklan ini sebagai ikon produk untuk menarik minat pembaca (fungsi informatif). Semua huruf nama produk ponsel iklan (8) ditulis dengan huruf kapital dan dibuat dalam ukuran yang besar. Hal ini bertujuan untuk memperkenalkan jenis ponsel.

\section{(9) LG Optimus PRO MAKSIMALKAN HARIMU DENGAN ANDROID “QWERTY TOUCH!”}

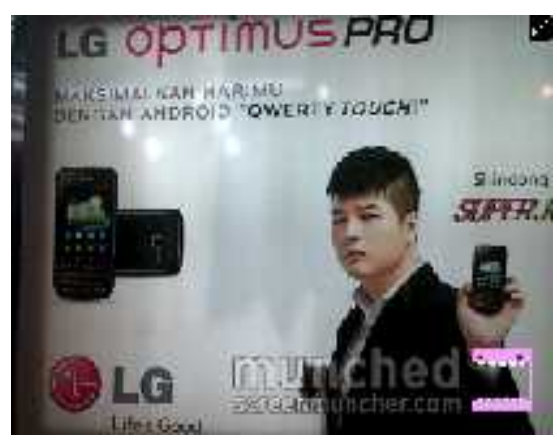

Sumber: BEC Bandung

Pola penulisan pada data iklan (9) berbentuk kalimat. Terdapat penegasan yang berupa kalimat perintah "Maksimalkan Harimu dengan Android" dan yang menjadi keunggulan dari telepon seluler ini ditulis dengan menggunakan tanda petik dan huruf kapital agar terlihat jelas sebagai hal yang penting untuk disampaikan kepada khalayak. Berdasarkan fungsi bahasanya, kalimat pada data iklan (9) termasuk ke dalam fungsi konatif, yaitu si penerima dilibatkan dalam penyampaian pesan. Dalam data iklan (9) si penerima dilibatkan secara langsung dalam proses komunikasi. Cirinya adalah adanya kata ganti persona kedua - $m u$ yang membuat pembaca merasa bahwa iklan itu ditujukan untuk dirinya. 


\section{(10) PAKE Cookie mini NYAMBUNG TERUS, NAMBAH SERUNYA!}

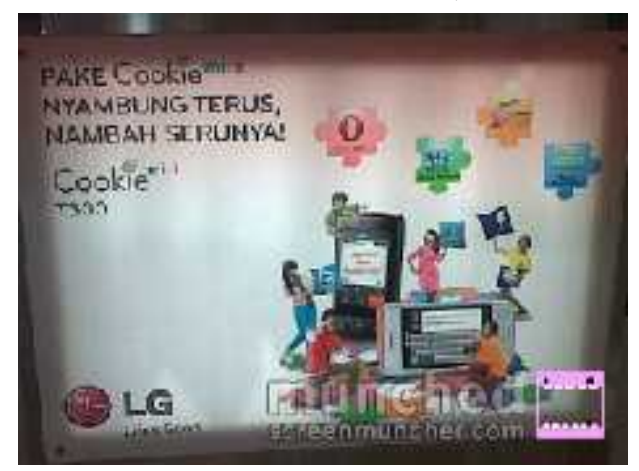

Sumber: BEC Bandung

Cookie mini T300 merupakan salah satu produk dari telepon seluler LG. Cookie mini adalah telepon seluler yang berukuran kecil dan memiliki banyak fasilitas seperti jaringan sosial, kemudahan mengakses informasi, dan kemudahan dalam menikmati musik. Sasaran iklan (target reader) pada produk ini adalah anak-anak muda karena fasilitas atau keunggulan yang dimiliki oleh telepon seluler ini sesuai dengan kebutuhan khalayak, khususnya anak-anak muda

Struktur pada data iklan (10) menggunakan pola dua klausa. Klausa pertama Nyambung Terus dan klausa yang kedua adalah Nambah Serunya. Klausa pertama Nyambung Terus memiliki makna fasilitas yang terdapat dalam telepon seluler ini bila digunakan tidak mengalami kesulitan dan terus terhubung (fungsi informatif). Klausa yang kedua Nambah Serunya masih berkaitan dengan bentuk klausa pertama. Hal tersebut bertujuan mempertegas makna klausa pertama dengan pilihan kata yang dapat memengaruhi pembaca (fungsi persuatif). Dengan demikian, kedua klausa pada data iklan (10) memiliki fungsi informatif sekaligus persuatif.

\section{PENUTUP \\ 4.1 Simpulan}

Berdasarkan medianya, iklan komersial ponsel yang dianalisis ini termasuk ke dalam iklan lini atas (above the line advertising). Menurut segi media cetaknya, iklan-iklan tersebut termasuk kelompok iklan display. Berdasarkan hasil kajian, dapat disimpulkan bahwa bentuk dan fungsi yang digunakan dalam iklan ponsel di Kota Bandung berupa penulisan huruf kapital secara keseluruhan dan penulisan huruf kapital hanya pada awal kata. Bahasa yang digunakan dalam iklan ponsel di Kota Bandung memiliki fungsi informatif dan persuatif (konatif).

\subsection{Saran}

Kajian dalam penelitian ini berfokus pada bentuk dan fungsi bahasa iklan ponsel di Kota Bandung. Data iklan yang diperikan pun masih terbatas. Oleh karena itu, diperlukan penelitian lanjutan yang mengkaji karakteristik bahasa pada iklan ponsel dari aspek lainnya dengan data yang berbeda. Dengan demikian, akan ditemukan kajian menyeluruh tentang bahasa pada iklan komersial, khususnya iklan ponsel.

\section{DAFTAR PUSTAKA}

Djajasudarma, T. Fatimah. 2010. Metode Linguistik: Ancangan Metode Penelitian dan Kajian (Cetakan Ketiga). Bandung: Eresco.

Jakobson, Roman. 1960 (1987). Linguistics and Poetics. Dalam Pomorska, K. \& Rudy, S. (ed.) Roman Jakobson, language in Literature, pp. 62-94. Cambridge, Mass., London, England: The Belknap Press of Harvard University Press. 
Asri Soraya Afsari: Karakteristik Penggunaan Bahasa dalam Iklan Ponsel di Kota Bandung

Kridalaksana, Harimurti. 2001. Kamus Linguistik Edisi Ketiga. Jakarta: PT Gramedia Pustaka Utama.

Mulyana, 2005. Kajian Wacana: Teori, Metode, \& Aplikasi Prinsip-Prinsip Analisis Wacana. Yogyakarta: Tiara Wacana.

Suryadi, Didih. 2011. Promosi Efektif: Menggugah Minat \& Loyalitas Pelanggan. Yogyakarta: ORYZA.

Suwandi, Sarwiji. 2008. Penggunaan Bahasa dalam Iklan Layanan Masyarakat. Dalam Sebalinguistik: Mengupas Pelbagai Praktik Berbahasa. Solo: Sebelas Maret University Press.

Tinarbuko, Sumbo. 2008Semiotika Komunikasi Visual: Metode Analisis Tanda dan Makna pada Karya Desain Komunikasi Visua . Yogyakarta: Jalasutra.

Widyatama, Rendra. 2011. Teknik Menulis Naskah Iklan: Agar Tepat Kena Sasaran. Yogyakarta: Penerbit Cakrawala.

Zaimar, Okke Kusuma Sumantri \& Ayu Basuki Harahap. 201. Telaah Wacana: Teori dan Penerapannya. Depok: Komodo Books. 
Asri Soraya Afsari: Karakteristik Penggunaan Bahasa dalam Iklan Ponsel di Kota Bandung 